\title{
A ICONOGRAFIA DAS CARTAS DE BARALHO
}

\author{
The iconography of the playing cards
}

SOARES, Kamyla Lemes

Universidade Federal de Juiz de fora

kamyla_dez@hotmail.com

\section{Resumo}

Durante o artigo será apresentado às características gráfico-visuais e simbólicas do jogo de cartas popularmente conhecido no Brasil como baralho, sendo investigados os aspectos materiais e imateriais que envolvem a configuração das cartas de baralho (suporte, formatos, significados e usos), do seu surgimento ao século XXI. Também será abordado de que forma o baralho pode ser usado na preservação da identidade cultural de um povo com exemplos de cartas criados por designers.

Palavras-chave: Design. Baralho. Identidade (identidade cultural).

\section{Abstract}

The article presents graphic-visual and symbolic characteristics of playing cards - popularly known in Brazil as "Baralho". It investigates the material and immaterial aspects involving the setting of playing cards (support, shapes, meanings, and uses), from their emergence to the twenty-first century. It will also cover how the cards can be used in preserving the cultural identity of a nation with sample cards created by designers.

Keywords: Design. Card game. Identity (cultural identity). 


\section{INTRODUC̣̃̃O}

Baralho】 é o nome que se dá a um conjunto de cartas com características gráficas e simbólicas pré-definidas, utilizado em jogos, em truques de mágica, para fins educativos, em testes psicológicos, entre outros. $\mathrm{O}$ baralho pode ir além das expectativas de um simples entretenimento e se demonstrar eficaz na preservação de uma identidade cultural levando em consideração que como afirma Nojima (1999, p. 15):

A leitura de mundo é antes de tudo visual e não-verbal. O uso do estímulo visual não-verbal para a comunicação é tão antigo quanto à civilização. As formas pictóricas, gráficas, holográficas com que se manifesta são testemunhos de que o homem sempre usou a linguagem visual.

Para Ono (2004) o designer, o profissional, é responsável pela relação do objeto com o usuário, e suas implicações na sociedade. Ainda para Ono (2004) o design tem como uma de suas dimensões tornar os produtos comunicáveis. Deste modo, a prática profissional dos designers deveria ser decisiva no desenvolvimento de suportes materiais, relações simbólicas e práticas dos indivíduos nas sociedades.

Fazendo com que o designer assuma um papel importante na conservação da identidade cultural, logo que:

Design é uma atividade que configura objetos de uso e sistemas de informação e, como tal, incorpora parte dos valores culturais que a cerca, ou seja, a maioria dos objetos de nosso meio são antes de mais nada a materialização dos ideais e das incoerências de nossa sociedade e de suas manifestações culturais assim como, por outro lado, anúncio de novos caminhos. Segundo, porque o Design, entendido como matéria conformada, participa da criação cultural [...] (BOMFIM, 1999, p. 150-151).

Segundo Santos (2006) cultura diz respeito à humanidade em sua totalidade e também a cada um dos povos, nações, sociedades e grupos humanos. Porém, os fenômenos culturais não se restringem somente ao campo das ideias, estão também relacionados às condições materiais (econômicas e tecnológicas) disponíveis (CANCLINI, 2008). 


\section{A HISTORIA DO BARALHO}

Apesar de haver contradições acerca do período e local de seu surgimento, há registros de sua chegada à Europa entre os séculos XIV e XV (FARIAS, 2005). Para Wintle (1987 apud FARIAS, 2005, p. 261), os jogos de cartas têm origem árabe, aonde o jogo era formado por quatro grupos de cartas numeradas de 1 a 10 e mais três cartas ilustradas, constituindo um total de 52 cartas. No entanto, outra hipótese levantada remete o aparecimento do baralho à China, juntamente com a invenção do papel no século $X$, e uma das pistas seria a identificação de cartas datadas desse período com naipes semelhantes aos ouros e paus (BERRY, 1995 apud FARIAS, 2005, p. 264). Para Berry (1995), as copas e espadas seriam uma contribuição árabe e as figuras utilizadas (rei, dama, rainha e valete) seriam invenções europeias que ainda hoje são mantidas no Ocidente.

De acordo com registros mais recentes, um dos primeiros baralhos fabricado na Europa foi o Tarô, durante o século XV, as cartas eram utilizadas inicialmente como trunfos ao jogo ocidental, entretanto devido o simbolismo das figuras, começou-se a acreditar que as cartas eram a expressão de correntes antigas de sabedoria como a cabala, o esoterismo ocidental, alquimia, budismo, iniciações egípcias, o cristianismo místico e a mitologia celta.

O jogo baralho é formado por vinte e duas cartas, sendo vinte e uma numeradas em algarismo romanos e a vigésima segunda identificada com a inscrição il matto", que significa o "louco" em italiano. No Tarô, essa carta representava a liberdade e acredita-se que pode ter inspirado a carta que representa o coringa no baralho contemporâneo (WINTLE, 2014). Com o tempo surgiu o baralho espanhol e o baralho italiano de quarenta cartas, até hoje usado no Brasil para jogos como o Truco ou a Escopa, surgiu também os baralhos alemães de trinta e seis ou trinta e duas cartas que é o mesmo baralho usado para o pôquer no Brasil, diferentemente do baralho inteiro (ás, 2 a 10, Rei, Rainha e valete) usado nos Estados Unidos (WINTLE, 2014). Os baralhos contemporâneos possuem de 32 á 52 cartas, sendo Rei, Rainha, valete e de 5 á 10 cartas de numero (FARIAS, 2005). Um dos principais elementos gráficos e simbólicos que caracteriza um baralho são os naipes, eles têm a função de forma quatro grupos com as cartas.

Em alguns países, como França, Itália e Espanha, os naipes foram padronizados em paus, copas, ouro e espadas. Já na Alemanha os naipes ganharam outros símbolos gráficos: a folha, o coração, o sino e o pinhão.

Inicialmente as cartas produzidas eram pintadas a mão, sendo um trabalho bastante demorado e artesanal, o que deixava o jogo muito caro, mas as cartas resultantes eram mais resistentes e duráveis, fazendo com que sobrevivessem ao tempo e manuseio. Também há relatos de cartas mais caras que foram 
produzidas a partir de gravuras em cobre, usando as habilidades do ourives e gravador com várias cores, incluindo ouro e prata. Estes cartões tinham mais detalhes e uma utilização mais naturalista da linha. Esses pacotes eram dados como presentes de casamento e deixados como herança, por serem considerados itens valiosos (WINTLE, 2014).

Durante o século XIV, com o surgimento da xilogravura, os layouts das cartas passaram a ser esculpidos em madeira, como é mostrado na figura 2, possibilitando que o jogo começasse a ser produzido em série. Mesmo ocasionando a diminuição dos custos de confecção e consequentemente barateando a comercialização dos baralhos, as cartas pintadas à mão não desapareceram por completo e passaram a ser tidas como artigo de luxo. Além do fato de serem pintadas à mão, uma a uma, as cartas de luxo eram confeccionadas com o acoplamento de seis tipos diferentes de papel tornando-as mais rígidas e resistentes, enquanto as produzidas em xilogravura utilizavam-se de apenas três tipos de papeis.

As cartas feitas em xilogravura tiveram suas cores aplicadas por meio de estêncil, que eram feitos de papel pintado em ambos os lados, com várias camadas de tintas a óleo. O bloco de madeira era esculpido com as imagens das cartas e a figura do rei exigia cinco estênceis, que é o número de suas cores. Os blocos de madeira esculpidos para cada naipe e eram impressos separadamente, e exigia um estêncil cada, as cartas tiveram uma rápida expansão pelos países da Europa, como também uma rápida aceitação pela sociedade.

Os baralhos atuais são produzidos com papel cartão com espessura de $290 \mathrm{~g}$ e em plástico PVC sendo estes impermeáveis e de grande durabilidade. As cartas são produzidas em impressoras offset ${ }^{1}$, o que permitiu uma fabricação em larga escala.

\section{Figura 1- Naipes de acordo com a região}

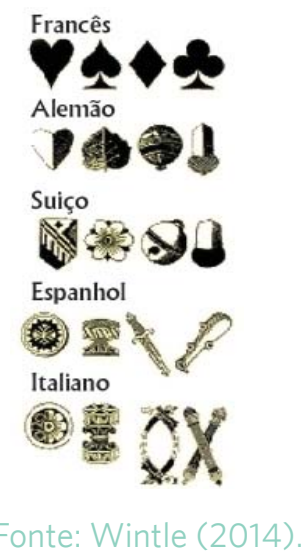

1 Processo de impressão planográfica para transferência de imagens e textos de uma matriz para o papel (ABIGRAF, 2003). 


\section{Figura 2 - Modelos de blocos esculpidos}

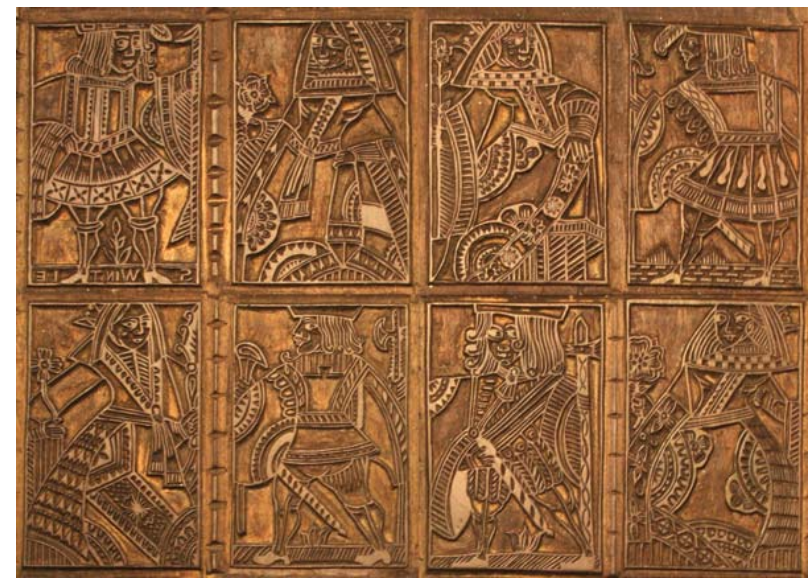

Fonte: Wintle (2014)

O baralho, hoje, ainda é muito difundido devido às inúmeras possibilidades de utilização e a sua popularização fez com que fossem criadas várias versões digitais dos seus jogos, possibilitando ao usuário jogar partidas sozinho (sem a participação de outros jogadores), ou até mesmo competir com outras pessoas online.

No entanto, apesar da capacidade de se adaptar às inovações do universo digital, o baralho sobrevive ao tempo e mantém alguns aspectos tradicionais, instituídos desde seus primeiros registros. Nesse sentido, podemos observar que as cartas preservam símbolos culturais e influências de cada região associada à sua origem, no entanto o baralho mudou alguns aspectos, pois com o tempo ele acumulou fragmentos de sua historia e se adaptou a novos modos de produção, suporte e usos.

As características culturais atreladas ao fácil manuseio, ao barateamento de sua produção e comercialização, e à popularização dos jogos, o baralho se transformou em um valioso objeto de estudos culturais (parte da nossa cultura material).

\subsection{Design e Significados}

As cartas são pedaços retangulares de papeis que possuem em média $6 \times 8 \mathrm{~cm}$, mas também existem as cartas miniaturizadas que são reduções de cerca de $50 \%$ do tamanho normal, normalmente fabricadas para o público infantil.

Segundo Farias (2005) a primeira característica a ser observada numa carta de baralho é o naipe adotado. O naipe é o símbolo presente em todas as cartas que indicam em qual dos quatro grupos a carta pertence.

Farias (2005) explica que os símbolos que distinguem os naipes das cartas 
de baralho podem ser classificados em quatro grandes grupos, de acordo com a sua origem:

\begin{abstract}
Os sistemas europeus podem ser divididos em quatro grupos: o latino (adotado na Espanha, Itália e Portugal), em que os naipes representam moedas, taças, espadas e bastões; o germânico, com representações de guizos, bolotas de carvalho, corações e folhas; o suiço, com guizos, bolotas de carvalho, escudos e flores; e o francês (depois adotado pelos ingleses e hoje empregado internacionalmente), com diamantes, corações, pás e trevos (FARIAS, 2005, p. 265).
\end{abstract}

Entretanto quando os portugueses migraram do sistema latino para o francês eles mantiveram o nome dos naipes (ouros, copas, espadas e paus), mesmo que sejam símbolos diferentes. No Brasil o sistema mais adotado é o francês, mesmo que a nomenclatura se mantenha a latina.

Quando a Inglaterra começou a cobrar impostos sobre as cartas produzidas, ela forçava as empresas a colocarem sua marca no baralho, normalmente a marca era colocada no ás de espadas, com o tempo a obrigatoriedade foi retirada, mas o costume continuou dando uma maior liberdade de criação nessa carta (FARIAS, 2005) como é visto na figura 3.

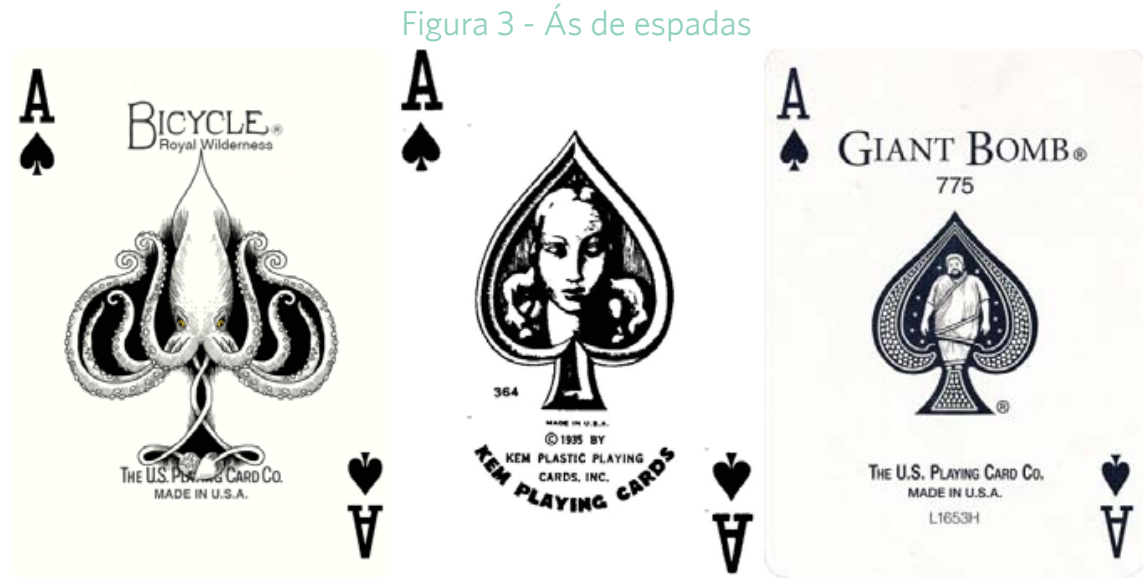

Fonte: Bicycle, Kem e Giant Bomb, 2015. ???? ou seria (FARIAS, 2005)???

As figuras surgiram na França entre 1450-1470, acreditava-se que elas foram inspiradas em grandes lideres, mas não houve nenhuma comprovação e acredita-se que esses símbolos se perderam no tempo. O que se sabe é que as cartas tinham a sua representação influenciada pelos costumes e indumentárias da época (BERRY, 1995). 
no Museu de Rouen representa o modelo a partir do qual, posteriormente, o pacote Inglês evoluiu. Quando a Inglaterra proibiu a importação de cartões em 1628, as gráficas usaram o pacote de Pierre como inspiração conforme observamos na figura 04.
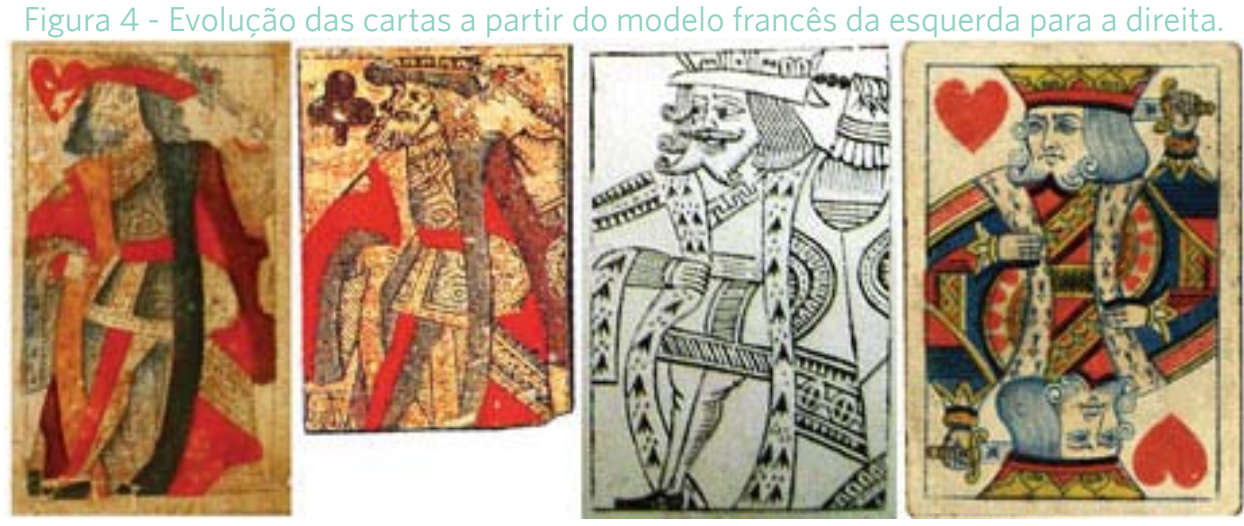

Fonte: Wintle (2014)

Segundo Mauger (1875) O cartão "Joker" ou coringa pode ter sido inventado por jogadores norte-americanos que, ao modificar as regras em algum momento durante os anos de 1860, decidiu que um trunfo extra, era necessário. Originalmente ele foi chamado de "The Best Bower" e depois "The little Joker" ou "The Jolly Joker" (WINTLE, 2014). Outra teoria é que o coringa foi inspirado na carta 22a do Tarô o il matto" (o "louco" em italiano), que representava a liberdade. A própria palavra, Joker, naturalmente poderia ter inspirado os cardmakers para representar bobos da corte, palhaços e outros brincalhões. No entanto, é encontrado não apenas os palhaços, mas também crianças, personagens de palco, animais, etc.

A escolha do bobo da corte foi lógica, pois completaria a corte no jogo, levando em consideração que na Europa a corte real foi o lar de palhaços, malabaristas e outros artistas. No entanto o coringa não foi uma invenção europeia, explicando assim o uso de outros elementos para representá-los, sendo que até hoje é uma das cartas com mais liberdade de representação (FARIAS, 2005).

No mesmo período de 1860, foi implantado outras melhorias como o arredondamento dos cantos, acabamentos refinados e o double-ended" que era o espelhamento das figuras para facilitar a visualização das cartas. Outra melhoria importante foi a criação dos índices, o mais popular eram as pequenas marcas em cantos diagonalmente opostos. Os índices continham o naipe e o caractere que representava a carta, sua criação também tinha o intuito de facilitar a visualização das cartas, quando estavam em formação de leque na mão dos jogadores (RUSSELL, 1885). 
Segundo Farias (2005) o dorso das cartas é o que permite uma maior variação, tradicionalmente possui qualquer tipo de ilustração. $O$ dorso deve ser idêntico em todas as cartas, durante o século $X X$ tornou-se comum uma moldura branca ao redor do desenho, para evitar que os cortes das cartas deixassem marcas de sangria que identificasse a carta, mas mesmo com esses cuidados jogadores mal intencionados e mágicos faziam pequenas alterações nos desenhos, para que a carta pudesse ser facilmente identificada.

\subsection{O baralho como Meio de Expressão Cultural}

No desenvolver da pesquisa, acreditamos na importância de exemplificar alguns baralhos que tem como uma de suas propostas preservar a identidade de uma determinada região e seus aspectos culturais.

\subsubsection{Teen Patti}

O ilustrador Anjali DSouza de Chennai, na Índia criou um baralho de cartas usando a arte popular indiana como inspiração. A motivação para o desenvolvimento desse baralho foi que com o surgimento dos jogos digitais, os adolescentes indianos estavam esquecendo-se dos tradicionais jogos de tabuleiros e jogos de cartas. A ideia era criar um novo avatar (personagem) e criar uma história através das cartas.

Figura 5 - Cartas Anjali DSouza

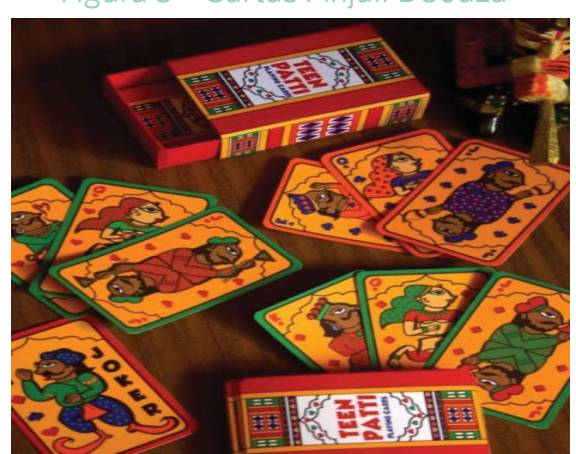

Fonte: Wintle (2014).

Figura 6 - Cartas Anjali DSouza

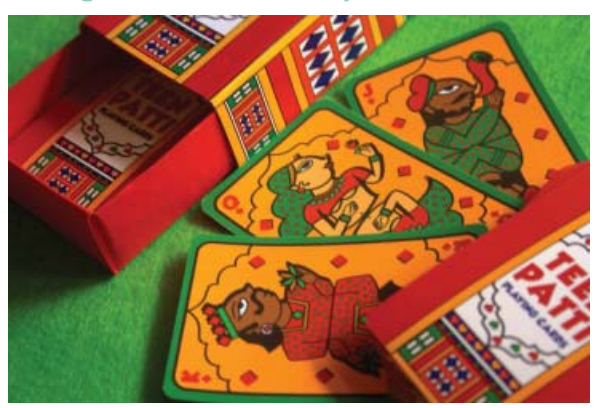

Fonte: Wintle (2014) 


\subsubsection{Diba Salimi}

Diba Salimi criou um pacote ilustrado à mão. As principais referências foram a história antiga persa, arte, esculturas e principalmente os tapetes persas. Os naipes recebem um elemento Tazhib que é usado em padrões nos tapetes persas. Cada um deles representa um momento único na história persa. Ela teve como objetivo deixar a arte persa mais acessível.

Figura 7 - Cartas Diba Salimi

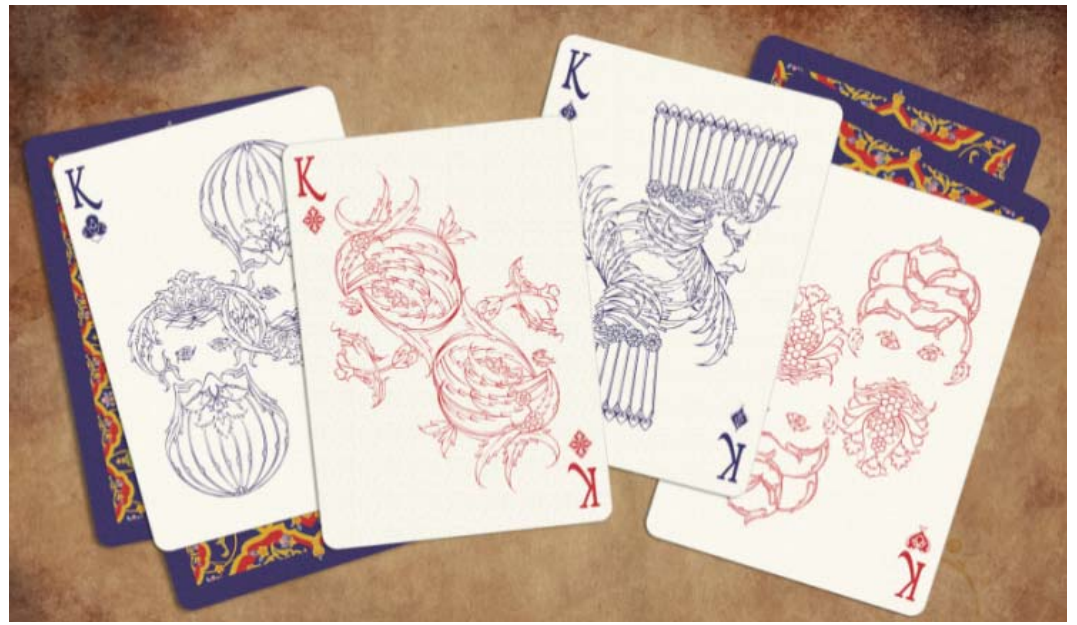

Fonte: Wintle (2014)

Figura 8 - Cartas Diba Salim

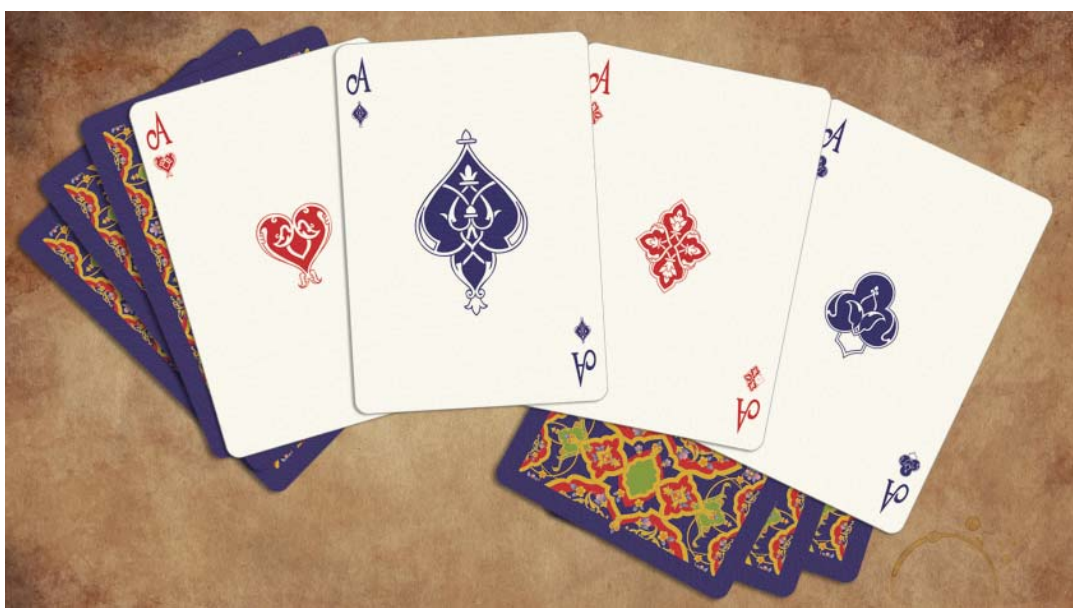

Fonte: Wintle (2014)

\subsubsection{E Brewstein}

As cartas produzidas por E Brewstein, traz um conjunto de "línguas perdidas" para ajudar a relembrar as antigas palavras e expressões da língua irlandesa. Cada carta tem um termo, a maneira que se pronuncia, o significado do mesmo e uma ilustração que o representa. Foi uma maneira encontrada para divulgar a herança linguistica irlandesa e resgatar expressões que estavam 
sumindo do vocabulário.

Figura 9 - Cartas E Brewstein

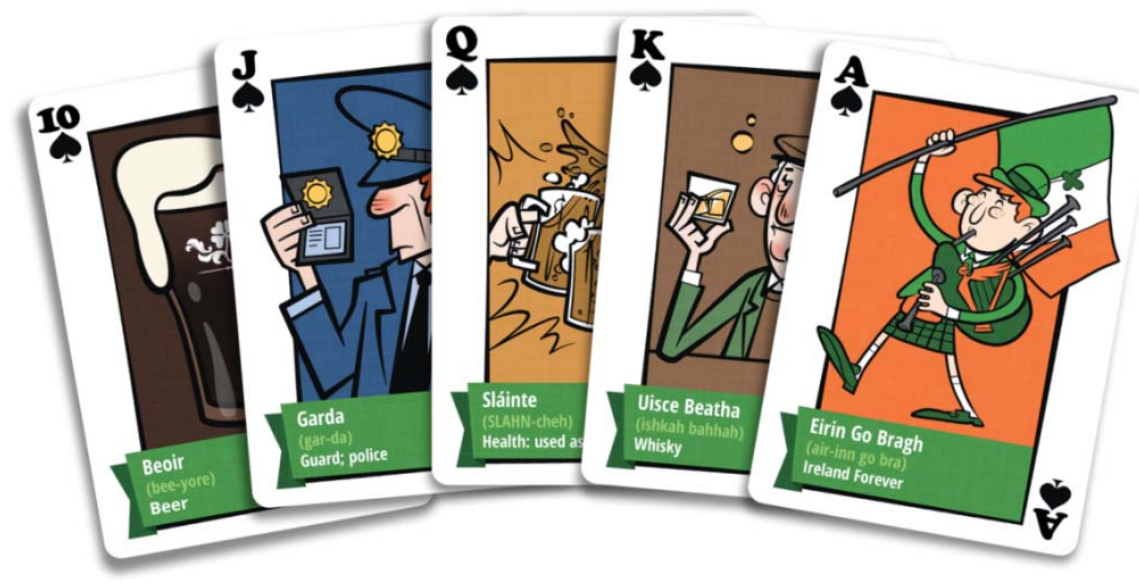

Fonte: Wintle (2014)

Figura 10 - Cartas E Brewstein

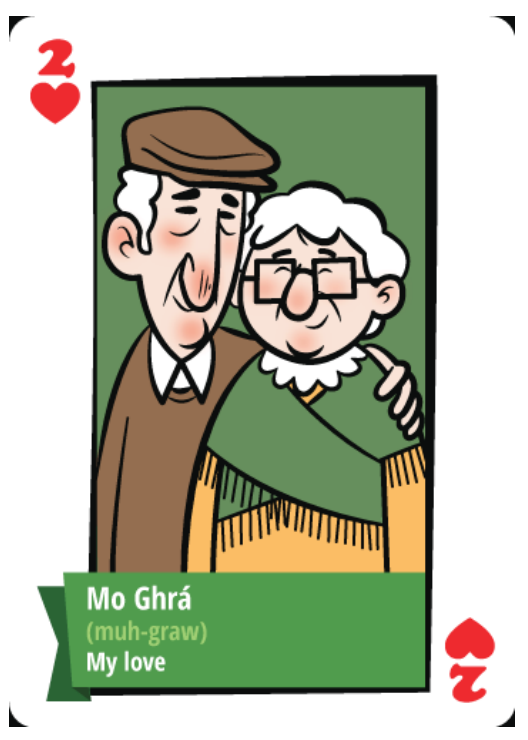

Fonte: Wintle (2014)

\section{CONSIDERAC̄ÕES FINAIS}

Com uma breve analise da historia do baralho já fica evidente o poder de autopreservação desse jogo, sendo que alguns elementos permaneceram imutáveis principalmente na diagramação e composição. Isso pode ser observado nos naipes que além de manter os mesmos símbolos, permanecem no mesmo local, além disso as cartas mantem as bordas arredondadas e a centralidade das ilustrações.

O design por meio de um processo metodológico utiliza o baralho como uma ferramenta de divulgação das tradições e dos elementos culturais e 
históricos de uma determinada região. O design fornece uma reinterpretação desses elementos com o objetivo de impedir o esquecimento das tradições pelas novas gerações e de propagar a cultura de um modo lúdico. O baralho aparece como uma maneira de unir e promover o conhecimento e realizar um renascimento desses elementos culturais.

\section{REFERÊNCIAS}

ABIGRAF - ASSOCIAÇÃO BRASILEIRA DA INDÚSTRIA GRÁFICA. Guia prático de orientação para questões de gestão ambiental para a indústria gráfica. São Paulo: ABIGRAF/ABTG, 2003.

BERRY, J. History of playing cards: the international playing-card society. 1995. Disponível em: <www.pagat.com/ipcs/history.html>. Acesso em: 25 mar. 2014.

BOMFIM, Gustavo Amarante. Coordenadas cronológicas e cosmológicas como espaço das transformações formais. In: Formas do design. Rio de Janeiro: 2AB, 1999.

CANCLINI, N. G. Culturas híbridas. 4. ed. São Paulo: Ed. Universidade de São Paulo, 2008.

FARIAS, P. Os baralhos da Copag entre 1920 e 1960. In: CARDOSO, Rafael (Org.). 0 design brasileiro antes do design: aspectos da história gráfica, 1870-1960. São Paulo: Cosac Naify, 2005. 360p.

MAUGER, V. Joker. 1875. Disponível em: <http://i-p-c-s.org/faq/ history_10.php>. Acesso em: 25 mar. 2014.

NOJIMA, V. L. Comunicação e leitura não verbal. In: COUTO, R. M. de S.; OLIVEIRA, A. J. de. Formas do design: por uma metodologia interdisciplinar. Rio de Janeiro: 2AB, 1999.

ONO, M. M. Design industrial e diversidade cultural: sintonia essencial. Estudos de casos nos setores automobilístico, moveleiro e de eletrodomésticos no Brasil. 2004. Tese (Doutorado em Arquitetura e Urbanismo) - Universidade de São Paulo, São Paulo, 2004.

RUSSELL, M. Double-headed courts. 1885. Disponível em: <http://i-pc-s.org/faq/history_9.php>. Acesso em: 27 mar. 2014.

SANTOS, J. L. dos. O que é cultura. 16. ed. São Paulo: Brasiliense, 2006. (Coleção Primeiros Passos). 
WINTLE, S. A 'moorish' sheet of playing cards: the world of playimg cards. Disponível em: <www.wopc.co.uk/history>. Acesso em: 27 mar. 2014. 